\title{
Design and Practice of Integrated Engineering Training Project based on CDIO Mode
}

\author{
Honghui Mu, Haiyan Wang, Guoqing Liu \\ Changchun University of Science and Technology, Changchun 130000, China \\ 270331219@qq.com
}

Keywords: CDIO, engineering simulated training, practical ability.

\begin{abstract}
This paper makes a proposal for improving students'engineering knowledge in four different aspects such as basic engineering knowledge, skills, group work and systematic abilities during engineering education, taking PLC engineering training as an example which is one of the projects of Engineering Training Center, Chang Chun University Of Science And Technology. This project puts a great emphasis on the students, who should learn to cooperate with one another and master theory in practice and have a test for their sense of engineering and practical ability by doing some simulated engineering projects.
\end{abstract}

\section{Introduction}

CDIO engineering education mode is the latest achievements of international engineering education reform in recent years, it representative Conceive-Design, Implement-Oprate. The project with CDIO from design, development to build the whole process of running reference to the teaching process of the course. The electrical engineering training center of Changchun science and Technology will be integrated CDIO engineering education model into the teaching process, that increase engineering training for course design and graduation design process, the engineering training course will be divided into modules, combined with the construction of school enterprise cooperation training .The industrial environment is introduced to the school as an engineering education environment, it improving students' engineering knowledge in four different aspects such as basic engineering knowledge, skills, group work and systematic abilities during engineering education. Set up the engineering training system based on the engineering project, engineering discipline integration training system associated with each other. The following will be the electronic information science and technology professional engineering training project as an example, a brief description of the integration of engineering training project design and project evaluation methods of exploration and practice.

\section{The basic framework of practical teaching system}

There are many kinds of disciplines and major differences in Colleges and universities. Each discipline and specialty has its own practical ability, so it is important to build up the corresponding practice teaching system. In general, practice teaching system in Universities have five subsystems, such as the experimental training and practice, comprehensive design, social practice, Innovative undertaking. Through the training of different teaching places in and out of the campus, we can reach the standard of practical ability.

\subsection{Experimental training subsystem}

The main goal of the experiment teaching is to improve the practical ability of the experiment, grasp the basic experimental skills and methods, integrate scientific knowledge, and promote scientific thinking and innovative thinking. Practical training is a kind of training for the students' special ability or comprehensive technical application ability. It enable students to master the actual work in professional field of basic skills and technical application ability through training. It can develop 
students' comprehensive application ability to solve practical problems through the simulation of production or production project simulation.

\subsection{Practice subsystem}

The purpose of practice is to enable students to understand the society, contact with reality, increase knowledge, enhance labor sense and responsible sense, and cultivate work independent ability. There are many kinds of forms, such as cognition, teaching, production and enhancement.

\subsection{Integrated design subsystem}

It is mainly composed of curriculum design, comprehensive design, graduation design and other aspects, it is an important part of the professional teaching plan in Colleges and universities. Through the comprehensive design practice teaching, enable students to consolidate the knowledge, the theoretical knowledge learned in the classroom teaching flexibly applied in practice, improve the students' ability to analyze and solve problems. In particular, Graduation design paper can train the students to explore the truth, strengthen the social consciousness and train the basic skills.

\subsection{Social practice subsystem}

The cultivation of students' innovative spirit and practical ability, not only need theoretical and experimental teaching and practice teaching, also need to be closely combined with the academic lectures, student associations, campus culture, social services and work study. Participate in various activities of social practice by college students, not only for students to carry out various cultural, sports, art, culture and talent skills, but also cultivate the comprehensive quality of the students. Students can learn how to behave, how to learn, how to work, also can make students more in-depth understanding of the society, strengthen the social responsibility consciousness.

\subsection{Innovation and entrepreneurship subsystem}

The universities mainly through open experiment, Students scientific research and technology activities, academic competition, entrepreneurship competition and other aspects implementing innovation and entrepreneurship education. Science and technology competition especially the Ministry of education sponsored by the discipline competition, is an effective carrier of innovation education. It has a positive significance in many aspects, such as promote the reform and development of university teaching, and promote the combination of teaching and research, students' learning motivation, cultivating students' innovative ability, cooperation spirit and theory with practical ability.

\section{The construction of the teaching system of engineering training in the private colleges}

The teaching system of engineering project training is based on the training of professional ability to design and select project, it is design to complete project operation process though knowledge, ability and quality structure. according to organization and implementation of teaching practice, the students though project planning, implementation, analysis and improvement process to achieve the goal of cultivation. Students in the implementation of the project in the process of learning knowledge, training skills, master technology, improve professional quality, to achieve training objectives.

This paper from the process of the status and role that the project training in Higher Education as the starting point, The overall goal is learn process knowledge, enhance the ability of engineering practice, improve the comprehensive quality and requirements ,to train innovation spirit and innovation ability, explore project training specific normative content and training mode.

\subsection{Selecting the appropriate project in the teaching of comprehensive training}

The content of engineering project teaching usually comes from the problems in the real life or a project task that needs to be solved. The project can be through the market research, direct access professional projects, or though careful designed, integrated molding, and then through the transplant, transformation or simplification of the project. The design and selection of the project should meet the following characteristics: Firstly, the practicality. The selection of the project should be in line with the reality of the current industry, introduce real projects, otherwise it will be out of touch with reality, students will not be interested in the future work. Secondly, the heuristic. The choice of the project should have a strong heuristic, contains a certain depth of the problem, can inspire thinking. The more 
attractive the problem, the more able to leave more space for thinking, the better the effect of teaching. Thirdly, the typical. The project should have general characteristics to reflect similar things for analogy things. Finally, the purpose. The selection of the project should be adapted to teaching purpose and requirements, it can improve students' ability to analyze and solve problems.

The project training is the process of teaching and practice, that transform objective law into the knowledge and skills, teachers will not impart knowledge and theory to students, but guide students to think and practice, master and use knowledge in practice. The role of the teacher is "coach", command and guide students to master the necessary knowledge of the project, to complete skills training, "the ball is to the students themselves to fight" (1). In the course of the implementation of the project training, we should emphasize the main role of the students, and promote the students to acquire knowledge by self-education. Let students understand the knowledge in the actual participation and experience, finally through teachers summary to enhance the knowledge into students' knowledge. Because of the students through personal experience master knowledge and skills, it is not easy to forget. The design of the training of each project break the focus and difficulty of the course, so students have a deep understanding of the problem, so students have the ability to analyze and solve problems with a solid foundation.

\subsection{Establishment of standardized teaching content and training model}

In practice, Compared with the comprehensive practical ability and quality training the theory of teaching are more difficult to grasp. The teachers who engaged in the training work of engineering project have different engineering ability, uneven concept and engineering consciousness, which will affect the effect of training project directly. In order to improve the training effect, It is strengthen the teacher's training engineering quality, it is also important for arrangement training contents and study methods, standardize teaching content, improve the rationality and practicability of the training process.

1) Normative content, modular teaching

The formalized content and method is the premise to ensure the overall teaching quality, it will not have a great difference for teacher's effect. This is also the difference between the modern engineering education and the teacher's teaching mode. Of course, the specific standardized project training for a period of a school training process. Due to the differences in the understanding of the equipment and engineering training, standardization is a relative concept. The practical training content is divided into modules, establish several modules, provide the contents and methods of each training module .

The whole project is divided into several sub modules, such as project requirement analysis, software and hardware and process analysis, control program design, equipment integration, installation and debugging. The contents, methods and objectives of each module are defined clearly. Control the training effect of each sub module, to ensure the teaching effect of the whole subject.

2) Easy and single firt, difficult and comprehensive last

Based on advanced manufacturing technology, automatic control technology, electrical technology, computer technology and precision machinery technology is a revolutionary achievement in recent decades, naturally become the essential training course in project content. However, the advanced manufacturing technology involves a wide range of knowledge, the ability of students to enter into the practical training of engineering projects is limited. Figure 1 is the PLC control assembly project subject training process, the principle of design of integrated module according to the subdivision from easy to difficult, the first single after the cooperation process, knowledge learning, ability training and innovation consciousness training combined. According to this process training, most students can successfully complete the training requirements of the subject. 


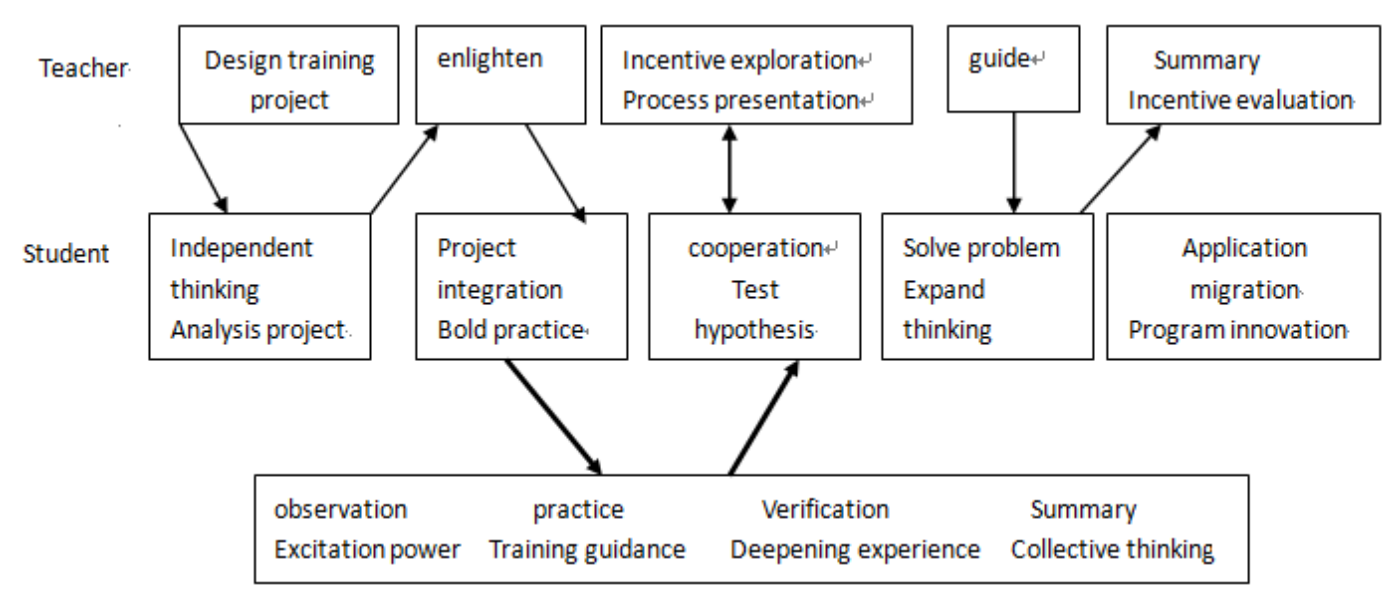

Figure 1. Basic flow chart of comprehensive training of engineering project

\section{Design of integrated engineering training project under CDIO mode}

The integration of engineering training project under CDIO mode is different from the experimental project, which combine the CDIO theory in the conception, design, implementation and operation contents of four stages in the process of teaching, with the actual needs of the project and the case as the background, are classified according to the cognition, skill training, case analysis and comprehensive application, reflects the project from the understanding, to imitate the training process engineering education of independent innovation, to prevent from the engineering project as a training course, let students understand and master the latest professional technology and industry development in the training process.

\subsection{Cognitive project}

In the engineering training project, engineering project is a cognitive knowledge level, first, students are required to master the equipment, tools and devices used in practical engineering, this project in accordance with the low-voltage electrical appliances, control components, actuator, common tools for classification, take physical form to let the students understand the device used in practical engineering structure using the method, and the selection principles in the circuit diagram, graphics, symbols and notations etc.. And related theory courses, so that students review the theoretical courses studied.

Table 1. Cognizing project and studying requirement

\begin{tabular}{|c|c|c|c|c|}
\hline number & classification & equipment & requirements & Contact course \\
\hline 1 & Basic device & $\begin{array}{c}\text { Button, Diodes, } \\
\text { transistors, resistors, } \\
\text { capacitors }\end{array}$ & $\begin{array}{c}\text { Distinguish } \\
\text { proficient in use }\end{array}$ & $\begin{array}{c}\text { PLC } \\
\text { electrotechnician }\end{array}$ \\
\hline 2 & $\begin{array}{c}\text { Automatic } \\
\text { control device }\end{array}$ & $\begin{array}{c}\text { PLC, Touch screen, } \\
\text { sensor,ATM8051 }\end{array}$ & $\begin{array}{c}\text { Function and using } \\
\text { method }\end{array}$ & $\begin{array}{c}\text { Principles and } \\
\text { Application of } \\
\text { Single-chip Computer }\end{array}$ \\
\hline 3 & $\begin{array}{c}\text { Auxiliary } \\
\text { device }\end{array}$ & $\begin{array}{c}\text { DuPont wire, chip } \\
\text { holder, mother pin, } \\
\text { circuit board }\end{array}$ & $\begin{array}{c}\text { Function and using } \\
\text { method }\end{array}$ & electrotechnician \\
\hline Commonly & $\begin{array}{c}\text { Multimeter, soldering } \\
\text { iron, stripping pliers }\end{array}$ & $\begin{array}{c}\text { Know and } \\
\text { understand the basic } \\
\text { function, learn to use }\end{array}$ & $\begin{array}{c}\text { Sensor and testing } \\
\text { technology }\end{array}$ \\
\hline
\end{tabular}

\subsection{Engineering skills training program}

The rapid development of modern industry requires a lot of practical experience and strong practical ability of college graduates, engineering skills training is a compulsory course in the cultivation of innovative talents, is the bridge that links theory and practice, in the professional comprehensive training process, we mainly from the aspects of system design, circuit principle diagram drawing 
principle, hardware circuit of welding map, hardware and software debugging and function realization to improve students' ability of electrical design and project implementation capacity. After this stage of training, students will be linked to the theory of knowledge and real equipment, not only improve the ability to practice, but also further consolidate the theoretical knowledge.

\subsection{Engineering case project}

In order to enable students to further understand the role and function of various types of automatic control equipment or components in the actual production, introduced in the course of teachers' cooperation with enterprises to succeed in a scientific research project as a case, jointly taught by teachers and engineers, enterprises from the shallower to the deeper, from easy to difficult to guide students to learn the knowledge and skills of application in practical engineering. Truly learning". Table 2 is the realization of temperature and humidity detection system based on MCU minimum system, from the first stage to the fifth stage, the basic will run through the main content, cognitive training and engineering skills, in the case of application in strengthening engineering skills at the same time, also let students understand the implementation process of a complete system engineering, for the foundation to carry out comprehensive training in the application of the next step. In the training of the enterprise standard requirements and technical specification document writing, let students in the learning process to an engineer's identity for themselves, regulate things; in training for professional characteristics of occupation moral education of students, inform the students as the occupation ethics of electrical and mechanical design personnel, with real examples to inform what students can, what things are impossible to do.

Table 2. Teaching content and requirement of real engineering project

\begin{tabular}{|c|c|c|}
\hline period & content & Teaching requirements \\
\hline 1 & $\begin{array}{l}\text { Schematic design of } \\
\text { system circuit }\end{array}$ & $\begin{array}{l}\text { According to the requirements of the subject, select components, } \\
\text { design circuit }\end{array}$ \\
\hline 2 & Schematic drawing & $\begin{array}{c}\text { Use Protel software to draw the hardware circuit diagram and } \\
\text { complete the electrical test }\end{array}$ \\
\hline 3 & Welding hardware circuit & Use the electric iron to complete the welding of the circuit \\
\hline 4 & $\begin{array}{c}\text { Hardware and software } \\
\text { debugging }\end{array}$ & Burn the program to the circuit board to complete the debugging \\
\hline 5 & Function realization & Complete the corresponding function \\
\hline
\end{tabular}

\section{Conclusion}

The CDIO mode integration engineering training implement nearly three years, achieved good teaching effect. The students of Changchun University of science and technology through the integration of engineering training system, Practical and design ability have made significant progress, they have achieved excellent results in the National Undergraduate Electronic Design Contest and the National College automatic control contest. graduates have also been welcomed and praised by employers. The integration of engineering training project is open, it conducive to cultivate students' innovative spirit, and improve the practical ability and engineering consciousness. but the integration of engineering training demand teachers have higher engineering background and project control ability, the training workload, so in teaching process requires a team to promote work, that bring difficult to promote training project.

\section{Acknowledgments}

This work was 2016 Education scientific planning subject in Jilin province;project title: The development and research of the comprehensive training program for the telecommunication specialty in the private university; Project approval no.: GH16576. 


\section{References}

[1] Ying-jie Ma,Xiao-li Fan. Based on CDIO mode of "communication principle" project development and practice teaching [J]. Journal of Beijing Electronics Science and Technology Institute, 2013, 21(3): 91-94.

[2] Yu-juan,Bai-lang. Research and Practice on the teaching of basic courses of electrical specialty based on CDIO model [J], Major Construction \& Course Construction. 2016, 1: 63-66

[3] Yellow single-stage rotary inverted pendulum [J]. The design and implementation of science and technology plaza, 2016, (6): 41-44.

[4] PuJianBo Peng Xiaole, Yin Yandong, Dai Mengxi, Fan Wenrui. Comparative study of the inverted pendulum control method [J]. Industrial instrumentation and automation devices, 2016, (02): $11-15$. 